\title{
Epithelium derived relaxing factor: myth or reality?
}

In 1980 Furchgott and Zawadski' first reported that removal of the endothelium prevented the relaxation of isolated arteries induced by acetylcholine. This discovery led to a revolution in the thinking of most vascular physiologists and pharmacologists, particularly as it became apparent that absence of the endothelium not only curtailed various vasodilator responses but also considerably augmented the contraction of vascular smooth muscle seen with several vasoconstrictor agents. ${ }^{23}$ In 1982 we decided to test whether the principle emerging from studies of vascular control-namely, that the cells lining the lumen of the arteries modulate the responsiveness of the underlying smooth muscle-applied to other tubular structures in the body. We therefore started to investigate the effect of removing the epithelium on the responsiveness of canine bronchi to bronchoconstrictor agents. The first goal was to determine whether it was possible to remove only the epithelial layer from the airways. This turned out to be feasible with gentle mechanical rubbing of the luminal surface of the bronchi. We learned to do this very carefully so that no morphological damage was obvious in the subepithelial layers. With this technique we found that the ability of the bronchial smooth muscle to depolarise and to contract or relax was unaltered and that removal of the epithelium did not alter the lengthtension characteristics of the preparations. ${ }^{48}$ Under these conditions we thought that we could reasonably assume that the intrinsic properties of the bronchial smooth muscle were unchanged. We found, however, that removal of the epithelial layer caused a pronounced shift to the left of the concentrationcontraction curve for histamine, 5-hydroxytryptamine (serotonin), and acetylcholine, the degree of shift being similar for the three bronchoconstrictor agonists. ${ }^{6} \mathrm{~A}$ similar degree of potentiation has been observed for different bronchoconstrictor agents by several investigators using isolated airways from various species, including man. ${ }^{79-19}$ Thus there is little doubt that the absence of the epithelium favours bronchoconstriction.

Address for reprint requests: Dr Paul M Vanhoutte, Department of Physiology and Biophysics, Mayo Clinic, Rochester, Minnesota 55905, USA.
Although the phenomenon of potentiation of bronchoconstriction by removal of the epithelium is established, the mechanism underlying it is still a matter for debate. It is tempting to assume that, like the endothelium, the airway epithelial cells release relaxing factor or factors that exert a braking effect on the underlying smooth muscle, but alternative explanations need to be considered. In the case of acetylcholine and 5-hydroxytryptamine the epithelial cells do not appear to play a part in the enzymatic degradation of the bronchoconstrictor agents, so potentiation following removal of the epithelium cannot be attributed to the disappearance of a metabolic sink. ${ }^{6}$ Such a mechanism may contribute, however, to the modulatory action of the epithelium on airway responsiveness to tachykinins ${ }^{20}$ and adenosine. ${ }^{21}$ Another explanation could be that the epithelial layer constitutes an important diffusion barrier, preventing the bronchoconstrictor agents from reaching airway smooth muscle. Because of the experimental conditions used in our laboratory (isometric tension recordings in rings of airways suspended between stirrups), such explanation seems unlikely as the bronchoconstrictor agents reach the preparations from the outside rather than from the luminal surface. Furthermore, removal of the epithelium also potentiates the contractions evoked by electrical activation of cholinergic nerves, a situation in which acetylcholine is released in the immediate vicinity of the smooth muscle in the depth of the tissue and in which epithelial diffusion barriers do not exist. ${ }^{622}$ The depolarisation seen in bronchial smooth muscle cell membrane exposed to exogenous acetylcholine is greater in preparations without epithelium; indeed, the extent of the depolarisation in the absence of epithelium is of greater magnitude than that observed in bronchi with epithelium for the same degree of contractions. ${ }^{8}$ This argues strongly against the idea that epithelium acts as a passive barrier that prevents acetylcholine from reaching the smooth muscle. Finally, the fact that removal of epithelium reduces the relaxation of the airway in response to the beta adrenergic agonists isoprenaline and tulobuterol, ${ }^{62324}$ methylxanthines, ${ }^{25}$ or an osmotic $\operatorname{load}^{26}$ cannot be attributed to the removal of either a metabolic sink or a diffusion barrier. Hence the most logical explanation for the epithelium dependency of 
2nd Order

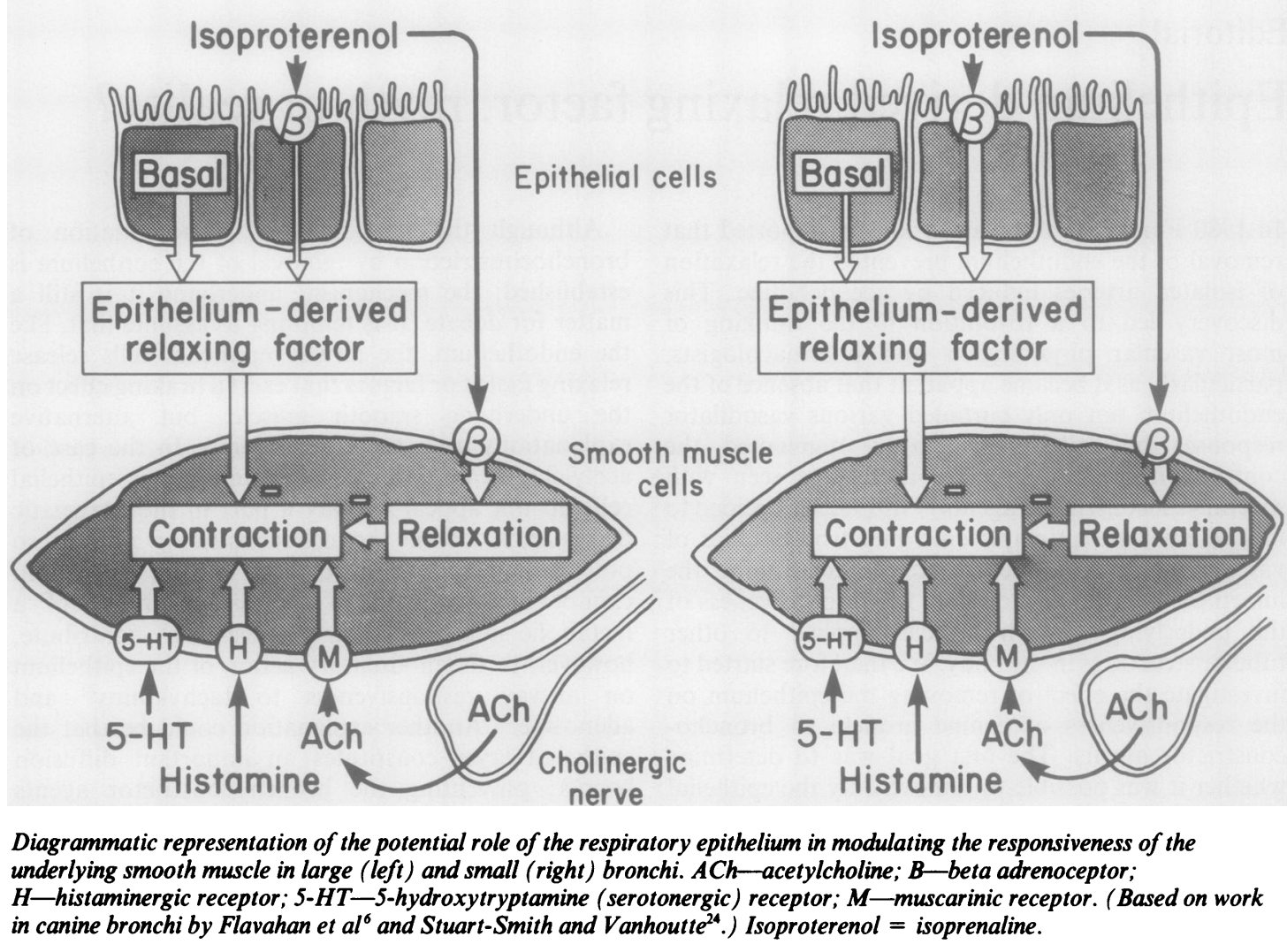

4th Order bronchial responsiveness is to assume that the airway epithelium releases a relaxing factor or factors that inhibit the underlying smooth muscle (figure) ${ }^{627} 28$

Several bioassay studies suggest that epithelium can secrete diffusible factors that relax bronchial or vascular smooth muscle. ${ }^{27} 2930$ There are, however, technical problems with these assays and the results are less conclusive than those of the studies showing the existence of endothelium derived relaxing factor or factors. The technical difficulties in bioassaying epithelium derived relaxing factors are probably due to the fact that epithelial cells, unlike endothelial cells, are highly polarised towards the underlying layers and to the likelihood that any epithelium derived relaxing factor secreted towards the lumen of the airways will be bound to or inactivated by mucus. Epithelium derived relaxing factor may have an even shorter half life than endothelium derived relaxing factor and this could also contribute to the difficulties of performing satisfactory bioassays.

Although we are reasonably confident that epithelium derived relaxing factor or factors exist we do not know its or their identity. Metabolites of arachidonic acid, in particular prostaglandin $\mathrm{E}_{2}$, are $\underset{\times}{\times}$ bronchodilators and cause epithelium dependent $\frac{\sigma}{7}$ relaxations. ${ }^{171-34}$ Inhibitors of cyclooxygenase, however, do not prevent the potentiating effect of epithelium removal on bronchoconstrictor responses. ${ }^{635}$ Epithelium derived relaxing factor seems very 윽 unlikely to be the same as endothelium derived $D$ relaxing factor or nitric oxide, as inhibitors of the latter two do not affect the shift of the acetylcholine N concentration-contraction curve after removal of the $\sigma$ epithelium, and nitric oxide is a poor relaxant of $N$ airway smooth muscle. ${ }^{3536}$ We do not know the exact $\underset{\mathrm{W}}{\mathrm{W}}$ nature of epithelium derived relaxing factor or factors 0 and are also uncertain whether it affects airway 0 smooth muscle directly. Indeed, the factor may well $\underset{\mathbb{D}}{\stackrel{C}{ }}$ act on other subendothelial structures (for example, $\stackrel{\odot}{\rightarrow}$ sensory nerves, blood vessels), which in turn could 0 modulate the responsiveness of the underlying smooth muscle.

With regard to the potential physiological role of $\frac{}{\mathbb{D}}$ epithelium derived relaxing factor, two major 
possibilities exist (figure). Firstly, the similar shift to the left of the concentration-contraction curves obtained with various agonists after removal of the epithelium implies that a basal release of the factor or factors exists and that this exerts a tonic restraint on airway smooth muscle. Interestingly, this tonic braking effect of the epithelium is more pronounced in larger than in smaller bronchi. ${ }^{24}$ We do not know what factors affect this basal release. Again by analogy with the blood vessels, changes in sheer stress could constitute an important natural stimulus, which could explain adjustments in diameter of the larger airway as a function of the flow of air through them. The second possibility is the occurrence of evoked (triggered) release of epithelium derived relaxing factor or factors, one potentially important trigger for their release being osmotic changes. ${ }^{26}$ Beta adrenergic activation appears to be another stimulus capable of triggering its release. This again has been shown to vary with the size of the airway, though in the opposite way to that found for basal release as the epithelium dependency of the response to isoprenaline is most pronounced in smaller airways. ${ }^{24}$ The role of the epithelium in the bronchodilator response to beta adrenergic agonists is in keeping with the autoradiographic localisation of beta adrenoceptors, which are particularly abundant on epithelial cells of the smaller airways. ${ }^{1037-40}$ It is tempting therefore to assume that epithelial beta adrenoceptors linked to the release of epithelium derived relaxing factor or factors may contribute to the efficacy of aerosol treatment with beta adrenergic agonists.

The role of eosinophils in the inflammation that characterises the asthmatic airways is emerging. Eosinophil major basic protein, considered to be the major toxin produced by these cells, causes an epithelium dependent augmentation of the contractions of airway smooth muscle evoked by acetylcholine or histamine. This hyperresponsiveness occurs at a time when the epithelial cells have not necrosed under the influence of the eosinophil toxin. ${ }^{41}$ To us this observation makes the link between the pharmacological studies following the effect of epithelium removal in normal airways and the pathology of asthma because asthmatic bronchi contain areas of epithelial denudation..$^{42}$ We propose that the absence of epithelial cells - and the resulting decrease in production of epithelium derived relaxing factormay be one of the modulating influences that combine to generate the airway hyperresponsiveness characteristic of the disease.

PM VANHOUTTE Department of Physiology and Biophysics Mayo Clinic and Foundation Rochester, Maryland, USA

\section{References}

1 Furchgott RF, Zawadzki JV. The obligatory role of endothelial cells in the relaxation of arterial smooth muscle by acetylcholine. Nature 1980;288:373-6.

2 Furchgott RF. The role of endothelium in responses of vascular smooth muscle to drugs. Annu Rev Pharmacol Toxicol 1984;24:175-97.

3 Vanhoutte PM, Rubanyi GM, Miller VM, Houston DS. Modulation of vascular smooth muscle contraction by the endothelium. Annu Rev Physiol 1986;48:307-20.

4 Aarhus LL, Rimele TJ, Vanhoutte PM. Removal of the epithelium causes bronchial supersensitivity to acetylcholine and 5-hydroxytryptamine. Fed Proc 1984;43:955.

5 Flavahan NA, Vanhoutte PM. Epithelial-dependent attenuation of bronchial smooth muscle tone. Fed Proc 1984;43:429.

6 Flavahan NA, Aarhus LL, Rimele TJ, Vanhoutte PM. The respiratory epithelium inhibits bronchial smooth muscle tone. J Appl Physiol 1985;58:834-8.

7 Stuart-Smith K, Vanhoutte PM. The airway epithelium modulates the responsiveness of porcine bronchial smooth muscle. J Appl Physiol (in press).

8 Gao Y, Vanhoutte PM. Removal of the epithelium potentiates acetylcholine in depolarizing canine bronchial smooth muscle. J Appl Physiol (in press).

9 Barnes PJ, Cuss FM, Palmer JB. The effect of airway epithelium on smooth muscle contractility in bovine trachea. Br J Pharmacol 1985;86:684-91.

10 Goldie RG, Papadimitriou JM, Paterson WJ, Rigby PJ, Self HM, Spina D. Influence of the epithelium on responsiveness of guinea-pig isolated trachea to contractile and relaxant agonists. $\mathrm{Br} J$ Pharmacol 1986;87:5-14.

11 Hay DWP, Robinson VA, Fleming WW, Fedan JS. Role of the epithelium in contractile responses of the guineapig isolated trachea. Fed Proc 1985;44:506.

12 Hay DWP, Farmer SG, Raeburn D, Robinson VA, Fleming WW, Fedan JS. Airway epithelium modulates the reactivity of guinea-pig respiratory smooth muscle. Eur J Pharmacol 1986a;129:11-8.

13 Hay DWP, Farmer SG, Racburn D, Muccitelli RM, Wilson KA, Fedan JS. Differential effects of epithelium removal on the responsiveness of guinea-pig tracheal smooth muscle to bronchoconstrictors. Br J Pharmacol 1987;92:381-8.

14 Hay DWP, Muccitelli RM, Horstemeyer DL, Wilson KA, Raeburn D. Demonstration of the release of an epithelium-derived inhibitory factor from a novel preparation of guinea-pig trachea. Eur $J$ Pharmacol 1987;136:247-50.

15 Hay DWP, Raeburn D, Farmer SG, Fleming WW, Fedan JS. Epithelium modulates the reactivity of ovalbumin-sensitized guinea-pig airway smooth muscle. Life Sci 1986b;38:2461-8.

16 Holroyde MC. The influence of epithelium on the responsiveness of guinea-pig isolated trachea. $\mathrm{Br} J$ Pharmacol 1986;87:501-7.

17 Tschirhart E, Frossard N, Bertrand C, Landry Y. Arachidonic acid metabolites and airway epitheliumdependent relaxant factor. J Pharmacol Exp Ther 
1987;243:310-6.

18 Raeburn D, Hay DWP, Robinson VA, Farmer SG, Fleming WW, Fedan JS. The effect of verapamil is reduced in isolated airway smooth muscle preparations lacking the epithelium. Life Sci 1986;38:809-16.

19 Raeburn D, Hay DWP, Farmer SG, Fedan JS. Epithelium removal increases the reactivity of human isolated tracheal muscle to methacholine and reduces the effect of verapamil. Eur J Pharmacol 1986;123: 451-3.

20 Frossard N, Barnes PJ. Effect of tachykinins on small human airways and the influence of thiorphan. Am Rev Respir Dis 1988;137:195.

21 Advenier C, Devillier P, Matran R, Naline E. Influence of epithelium on the responsiveness of guinea-pig isolated trachea to adenosine. Br J Pharmacol 1988;93:295-302.

22 Vanhoutte PM, Flavahan NA. Modulation of cholinergic neurotransmission in the airways. In: Kaliner MA, Barnes PJ, eds. The airways: neural control in health and disease. New York: Dekker, 1987:203-16.

23 Ruff F, Zander JF, Edoute Y, et al. Beta ${ }_{2}$-adrenergic responses to tulobuterol in airway smooth muscle, vascular smooth muscle and adrenergic nerves. $J$ Pharmacol Exp Ther 1987;244:173-80.

24 Stuart-Smith K, Vanhoutte PM. Heterogeneity in the effects of epithelium removal in the canine bronchial tree. J Appl Physiol 1987;63:2510-5.

25 Busk M, Vanhoutte PM. The methylxanthine, S 9795, causes the release of an epithelium-derived relaxing factor [abstract]. Clin Res 1988;36:590A.

26 Munakata M, Mitzner W, Menkes H. Osmotic stimuli induce epithelial-dependent relaxation in the guinea pig trachea. J Appl Physiol 1988;64:466-71.

27 Flavahan NA, Vanhoutte PM. The respiratory epithelium releases a smooth muscle relaxing factor [abstract]. Chest 1985;87(suppl):189-90S.

28 Vanhoutte PM. Airway epithelium and bronchial reactivity. Can J Physiol Pharmacol 1987;65:448-50.

29 Laitinen LA, Heino M, Laitinen A, Kava T, Haahtela T. Damage of the airway epithelium and bronchial reactivity in patients with asthma. Am Rev Respir Dis 1985;131:599-606.

30 Ilhan M, Sahin I. Tracheal epithelium releases a vascular smooth muscle relaxant factor: demonstration by bioassay. Eur J Pharmacol 1987;131:293-6.

31 Goldie RG, Fernandes LB, Paterson JW. Release and
- transfer of airway epithelium-derived relaxant factor (EpDRF) in a co-axial bioassay system. Am Rev Respir Dis 1988;137:101.

32 Flavahan NA, Danser AJ, Vanhoutte PM. Arachidonic acid and calcium ionophore cause epithelium-dependent relaxation of canine bronchial smooth muscle [abstract]. In: Proceedings of International Union of Physiological Sciences: meeting in Vancouver 13-18 July 1986: 148.

33 Stuart-Smith K, Vanhoutte PM. Arachidonic acid evokes epithelium-dependent relaxations of canine bronchi. Pharmacologist 1987;29:365.

34 Butler GB, Adler KB, Evans JN, Morgan DW, Szarek JL. Modulation of rabbit airway smooth muscle responsiveness by respiratory epithelium. Involvement of an inhibitory metabolite of arachidonic acid. $A m R e v$ Respir Dis 1987;135:1099-1104.

35 Farmer SG, Hay DWP, Raeburn D, Fedan JS. Relaxation of guinea-pig tracheal smooth muscle to arachidonate is converted to contraction following epithelium removal. Br J Pharmacol 1987;92:231-6.

36 Lorenz RR, Gao Y, Vanhoutte PM. The effect of epithelium removal on airway contractility is not mediated by arachidonic acid metabolites or nitric oxide. Physiologist (in press).

37 Shikano K, Berkowitz BA. Endothelium-derived relaxing factor is a selective relaxant of vascular smooth muscle. $J$ Pharmacol Exp Ther 1987;243:55-60.

38 Xue Q-F, Maurer R, Engel G. Selective distribution of

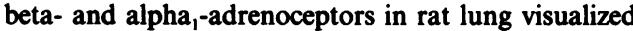
by autoradiography. Arch Int Pharmacodyn Ther 1983;266:308-14.

39 Carstairs JR, Nimmon AJ, Barnes PJ. Autoradiographic localisation of $\beta$-adrenoceptors in human lung. Eur $J$ Pharmacol 1984;103:189-90.

40 Carstairs JR, Nimmon AJ, Barnes PJ. Autoradiographic visualization of $\beta$-adrenoceptor subtypes in human lung. Am Rev Respir Dis 1985;132:541-7.

41 Argarwal DK, Schugel JW, Townley RG. Comparison of beta adrenoceptors in bovine airway epithelium and smooth muscle cells. Biochem Biophys Res Commun 1987;148:178-83.

42 Flavahan NA, Slifman NR, Gleich GJ, Vanhoutte PM. Human eosinophil major basic protein causes hyperreactivity of respiratory smooth muscle. Am Rev Respir Dis (in press). 